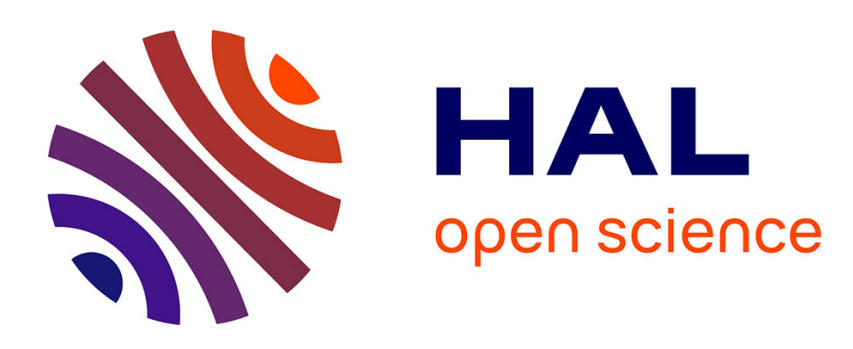

\title{
Automatic detection of sound knots and loose knots on sugi using gray level co-occurrence matrix parameters
}

\author{
$\mathrm{Hu}$, Min, Yun, Wang, Zhang
}

\section{To cite this version:}

$\mathrm{Hu}$, Min, Yun, Wang, Zhang. Automatic detection of sound knots and loose knots on sugi using gray level co-occurrence matrix parameters. Annals of Forest Science, 2011, 68 (6), pp.1077-1083. 10.1007/s13595-011-0123-x . hal-00930693

\section{HAL Id: hal-00930693 https://hal.science/hal-00930693}

Submitted on 1 Jan 2011

HAL is a multi-disciplinary open access archive for the deposit and dissemination of scientific research documents, whether they are published or not. The documents may come from teaching and research institutions in France or abroad, or from public or private research centers.
L'archive ouverte pluridisciplinaire HAL, est destinée au dépôt et à la diffusion de documents scientifiques de niveau recherche, publiés ou non, émanant des établissements d'enseignement et de recherche français ou étrangers, des laboratoires publics ou privés. 


\title{
Automatic detection of sound knots and loose knots on sugi using gray level co-occurrence matrix parameters
}

\author{
Chuanshuang Hu $\cdot$ Xiao Min • Hong Yun • Ting Wang • \\ Shikang Zhang
}

Received: 8 December 2010 /Accepted: 18 April 2011 / Published online: 24 August 2011

(C) INRA and Springer Science+Business Media B.V. 2011

\begin{abstract}
- Context Knowledge of the occurrence of sound and loose knots on the surface of sawn sugi (Cryptomeria japonica L.f.) is important for its grading and application.

- Objectives This study examined an optical system for detecting sound and loose knots in sugi instead of human being using the combining information of the color and texture features.

- Methods The proposed system could be conceptually divided into two components: a CCD camera scanning system and a defect detecting algorithm developed by the authors. In the algorithm, the contrast parameter calculated from a graylevel co-occurrence matrix was used to locate the potential defects represented by sound knots and loose knots. The rulebased approach, which was built according to the color feature histograms, was used to identify sound knots and loose knots. A series of samples containing single or multiple sound and/or loose knots were selected at random to verify the efficiency and accuracy of the proposed system.

- Results There were 94 sound knots and 86 loose knots on the surfaces of these samples, and the accuracy of locating the positions of sound knots and loose knots was $94.7 \%$ and $97.6 \%$, respectively. The accuracies of identifying knots as sound or loose were $96.6 \%$ and $98.8 \%$, respectively. The overall detection accuracy of the system was 93.9\%.
\end{abstract}

\section{Handling Editor: Barry Gardiner}

C. Hu $(\bowtie) \cdot H$. Yun $\cdot$ T. Wang $\cdot$ S. Zhang

Faculty of Forestry, South China Agricultural University,

Guangzhou 510642, People's Republic of China

e-mail: cshu@scau.edu.cn

\section{Min}

School of Architecture, South China University of Technology,

Guangzhou 510642, People's Republic of China
- Conclusions The results indicate that the proposed vision system is an efficient means of detecting sound knots and loose knots.

Keywords Wood quality · Defect detection · Knots - Image processing

\section{Introduction}

Sugi (Cryptomeria japonica L.f.) is the main wood species in Asian countries, especially Japan. However, the presence of many defects such as splits, holes, sound knots, and loose knots is well recognized. The detection of defects is currently performed by a skilled worker. However, human inspection is unsatisfactory because of subjective judgment. To automatically detect wood defects, optical, ultrasonic, microwave, nuclear magnetic resonance, X-ray, temperature gradient methods, and tracheid scanning have been used (Szymani and McDonald 1981; Portala and Ciccoteli 1992; $\mathrm{Hu}$ et al. 2002; Johansson et al. 2003). The optical method has been recognized as a promising technique and some optical systems have been developed to detect wood surface features. Recently, the color line scan camera was used to automatically optimize crosscut and to sort red oak edge panel parts (Conners et al. 1997) and the color feature histograms were used to separate wood defects into eight categories (Koivo and Kim 1989). However, the appearance of wood varies greatly and there are no two boards or defects that have the same properties of color or texture. Because there are still many problems associated with the detection of defects, it is necessary to develop new detection systems for automatic wood inspection.

Texture is defined as a pattern that is repeated and is represented on the surface or structure of an object. Gray 
level co-occurrence matrix (GLCM) parameters are used as a texture descriptor in the process of feature extraction. In this study, we report on a vision system that has been developed to detect sound knots and loose knots using texture information based on the GLCM method together with the color feature histogram.

\section{Materials and methods}

The materials selected for the experiment were sugi $(C$. japonica L.f.) samples measuring $1,000(\mathrm{~L}) \times 300(\mathrm{~T}) \times$ $20 \mathrm{~mm}(\mathrm{R})$. The numbers of the training and verifying sample sets were 222 and 160 , respectively. The moisture content was about $14 \%$ and the average specific gravity was 0.47 . All the samples were machined with a planer under the same conditions. The feeding speed was $15 \mathrm{~m} / \mathrm{min}$ and the cutting speed of the cutting blade was $30 \mathrm{~m} / \mathrm{s}$. The schematic diagram of the detection system is shown in Fig. 1. It consisted of a compact vision system (CVS 1456, NI), a CCD camera (Balser scA 1390-17 fc, Balser Vision Technologies), two flood lamps (Toshiba reflector 150WF), a computer numerical control (CNC) working table (Funuc M180 series), and a host computer equipped with a software system developed and installed by the authors. The samples were placed on the two-dimensional CNC working table and illuminated by the flood lamps from two sides. By adjusting the height and the focus of the digital camera, the images were captured at $60 \mathrm{dpi}$ and they were recorded as RGB images of dimensions of about $270 \times 200 \mathrm{~mm}$. The computer program was written in MatLab 7.0 as code resource. The flow chart of the program is shown in Fig. 2.

\subsection{Image processing algorithms}

After capturing and inputting the image, the R (red), G (green), and B (blue) signal images and gray image (8 bits) were generated from the RGB image ( 24 bits). The whole gray image was divided into $N_{\mathrm{r}} \times N_{\mathrm{c}}($ horizontal $\times$ vertical) subsets to calculate the GLCM. GLCM is a discrete function of distance and direction. The distance $d$ between two relational pixels was set to be 1 for micro-texture analysis. Here the angle was set to be $0^{\circ}$ or $90^{\circ}$ and an

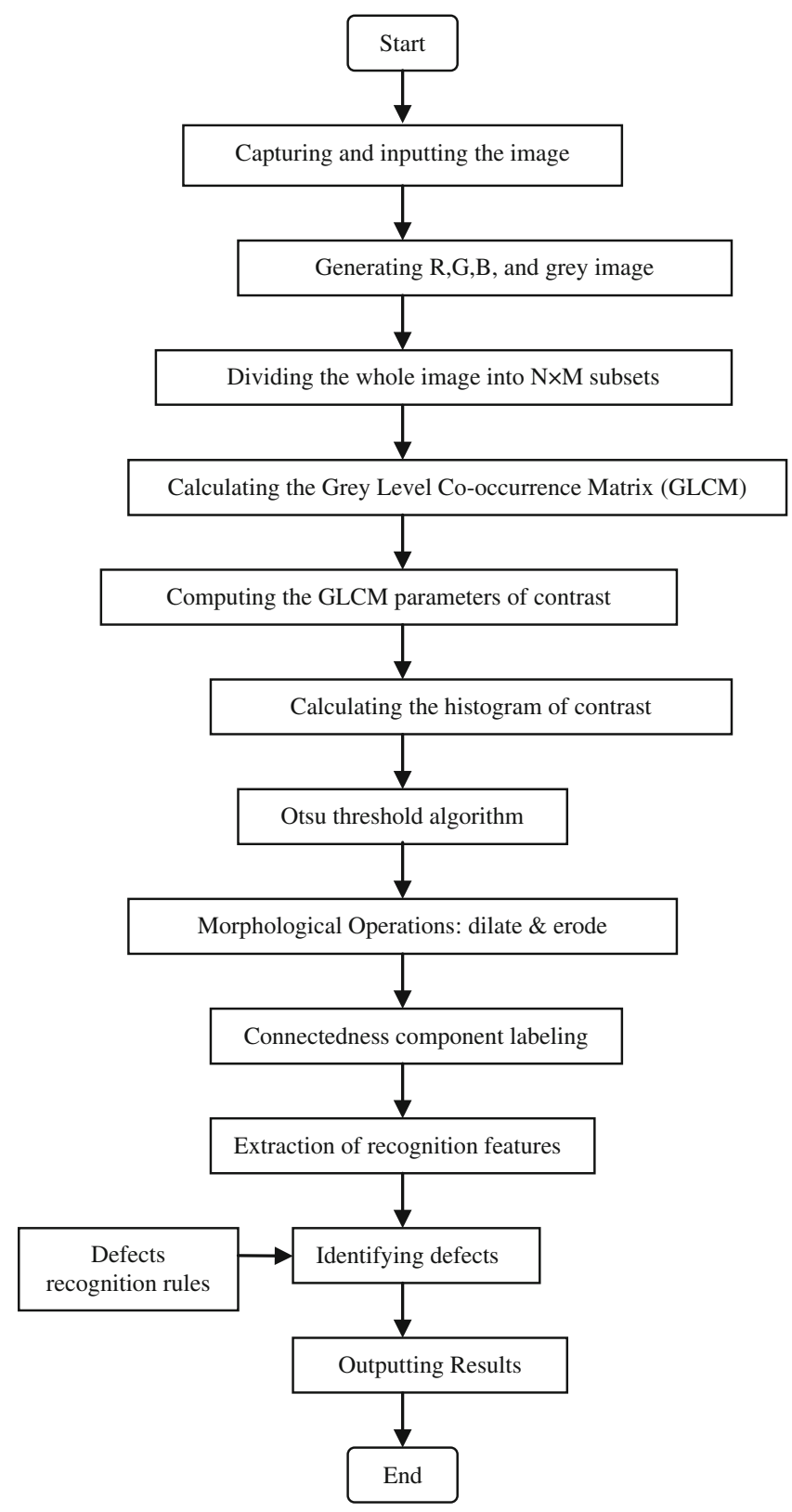

Fig. 2 Flow chart for the detection algorithm

adequate gray level quantization, $\mathrm{G}$ of 16 levels was used to construct the GLCM. The displacement vector $p(i, j \mid d, \theta)$ can be expressed by the following Eqs. 1 and 2
Fig. 1 Schematic diagram of the machine vision system

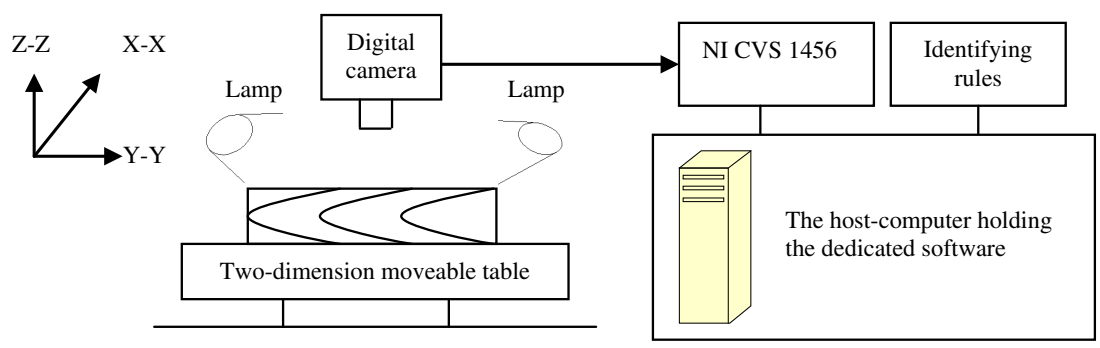


Table 1 Rules identifying sound and loose knots

$s k$ sound knot, lk loose knot

\begin{tabular}{|c|c|c|c|c|c|c|c|}
\hline \multicolumn{2}{|c|}{ Identifying rules } & \multicolumn{2}{|c|}{ Confidence value } & \multicolumn{2}{|c|}{ Identifying rules } & \multicolumn{2}{|c|}{ Confidence value } \\
\hline Features & Thresholds & sk & $\mathrm{lk}$ & Features & Thresholds & sk & $\mathrm{lk}$ \\
\hline \multirow[t]{2}{*}{$\mathrm{M}_{\mathrm{G}}$} & $M_{G} \in[57,116]$ & 1.0 & 0 & \multirow[t]{2}{*}{$\mathrm{V}_{\mathrm{G}}$} & $V_{G} \in[12,34]$ & 1.0 & 0 \\
\hline & $M_{G} \in[35,75]$ & 0 & 1.0 & & $V_{G} \in[33,53]$ & 0 & 1.0 \\
\hline \multirow[t]{2}{*}{$\mathrm{V}_{\mathrm{B}}$} & $V_{B} \in[9,33]$ & 1.0 & 0 & \multirow[t]{2}{*}{$\mathrm{V}_{\mathrm{R}}$} & $V_{R} \in[15,37]$ & 1.0 & 0 \\
\hline & $V_{B} \in[33,54]$ & 0 & 1.0 & & $V_{R} \in[31,54]$ & 0 & 1.0 \\
\hline
\end{tabular}

when $\theta$ is set to be $0^{\circ}$ or $90^{\circ}$ and the subset $N_{\mathrm{r}} \times N_{\mathrm{c}}$ is set to be $2 \times 2$ pixels.

$$
\begin{aligned}
& p(i, j \mid d, 0)=p(i, j \mid d, 0)+1 \\
& \quad \text { if }\left\{\begin{array}{l}
{\left[\left(x_{1}, y_{1}\right),\left(x_{2}, y_{2}\right)\right] \in\left(N_{\mathrm{r}} \times N_{\mathrm{c}}\right)} \\
\left|y_{1}-y_{2}\right|=0,\left|x_{1}-x_{2}\right|=d, f\left(x_{1}, y_{1}\right)=i, f\left(x_{2}, y_{2}\right)=j
\end{array}\right.
\end{aligned}
$$

$$
\begin{aligned}
& p(i, j \mid d, 90)=p(i, j \mid d, 90)+1 \\
& \quad \text { if }\left\{\begin{array}{l}
{\left[\left(x_{1}, y_{1}\right),\left(x_{2}, y_{2}\right)\right] \in\left(N_{\mathrm{r}} \times N_{\mathrm{c}}\right)} \\
\left|y_{1}-y_{2}\right|=d,\left|x_{1}-x_{2}\right|=0, f\left(x_{1}, y_{1}\right)=i, f\left(x_{2}, y_{2}\right)=j
\end{array}\right.
\end{aligned}
$$

Where $N_{\mathrm{c}}$ and $N_{\mathrm{r}}$ are the horizontal and vertical pixels of the object image, respectively. $\left(x_{1}, y_{1}\right)$ and $\left(x_{2}, y_{2}\right)$

Fig. 3 An example RGB image showing a sound knot (top center) and dead knot (bottom right)

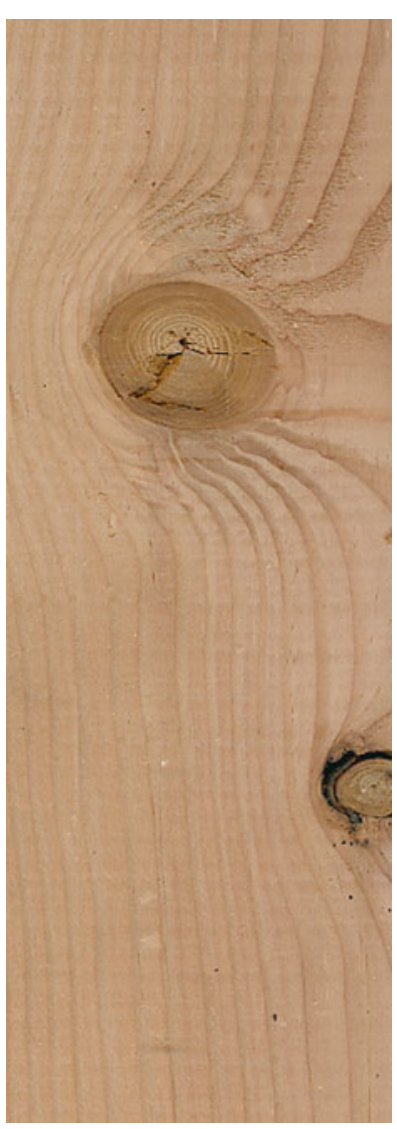

represents the spatial positions of the two neighboring pixels where their distance is $d$.

Haralick proposed 14 statistical features extracted from gray level co-occurrence matrices for use in image processing (Haralick et al. 1973). In this study, the contrast parameter was used as a distinguishing feature to detect potential defects from clear wood areas. The contrast parameter can be expressed by Eq. 3:

$f_{\mathrm{CON}} \mid \theta=\sum_{i=0}^{N} \sum_{j=0}^{N}(i-j)^{2} p(i, j \mid d, \theta)$

Where $N$ equals the gray level quantization, $\mathrm{G} ; \theta$ is $0^{\circ}$ or $90^{\circ}$.

To separate pixels of clear wood areas from pixels that might be a potential defect, Otsu's method was performed

Fig. 4 The binary image of the example in Fig. 3 after segmentation

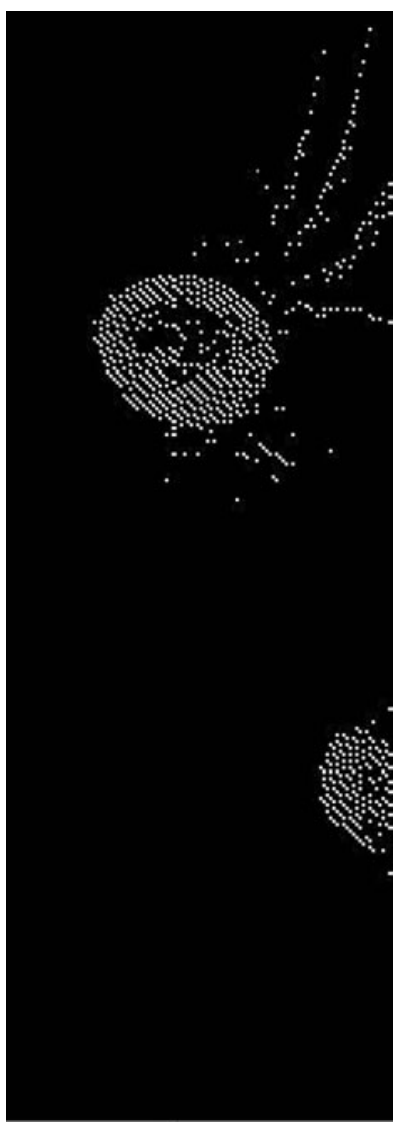


Fig. 5 The binary image post processing after morphological

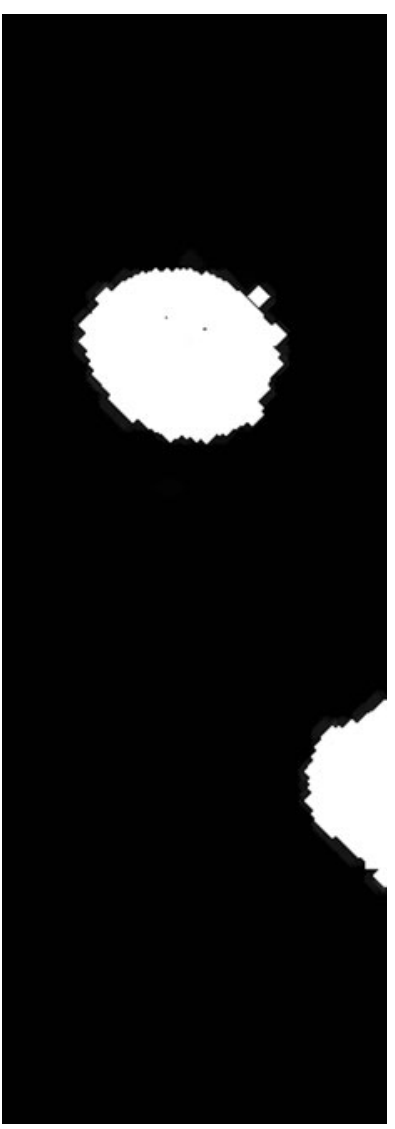

on the intensity histogram of the contrast parameter (Otsu 1979) as discussed below. The contrast parameter has intensity level range [min, $\max ]$ and set $k$ as any number between min and max. Let $n(i), N\left(N=\sum_{i=0}^{255} n(i)\right)$ denotes the frequency with which intensity level $(i)$ occurs in the whole range and the total number in the whole image. The probability of an intensity level $(P(i))$ can be denoted by Eq. 4 .

$P(i)=\frac{n(i)}{N}(i=0,1, \ldots, 255)$

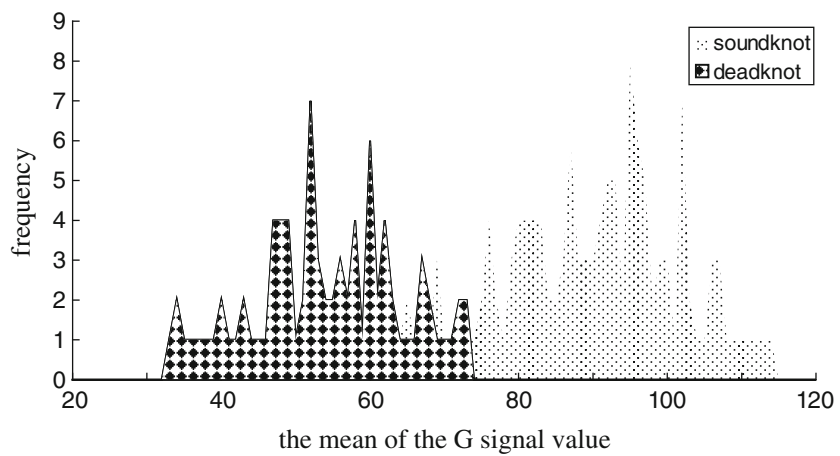

Fig. 6 The feature histogram of the mean for the $G$ signal value
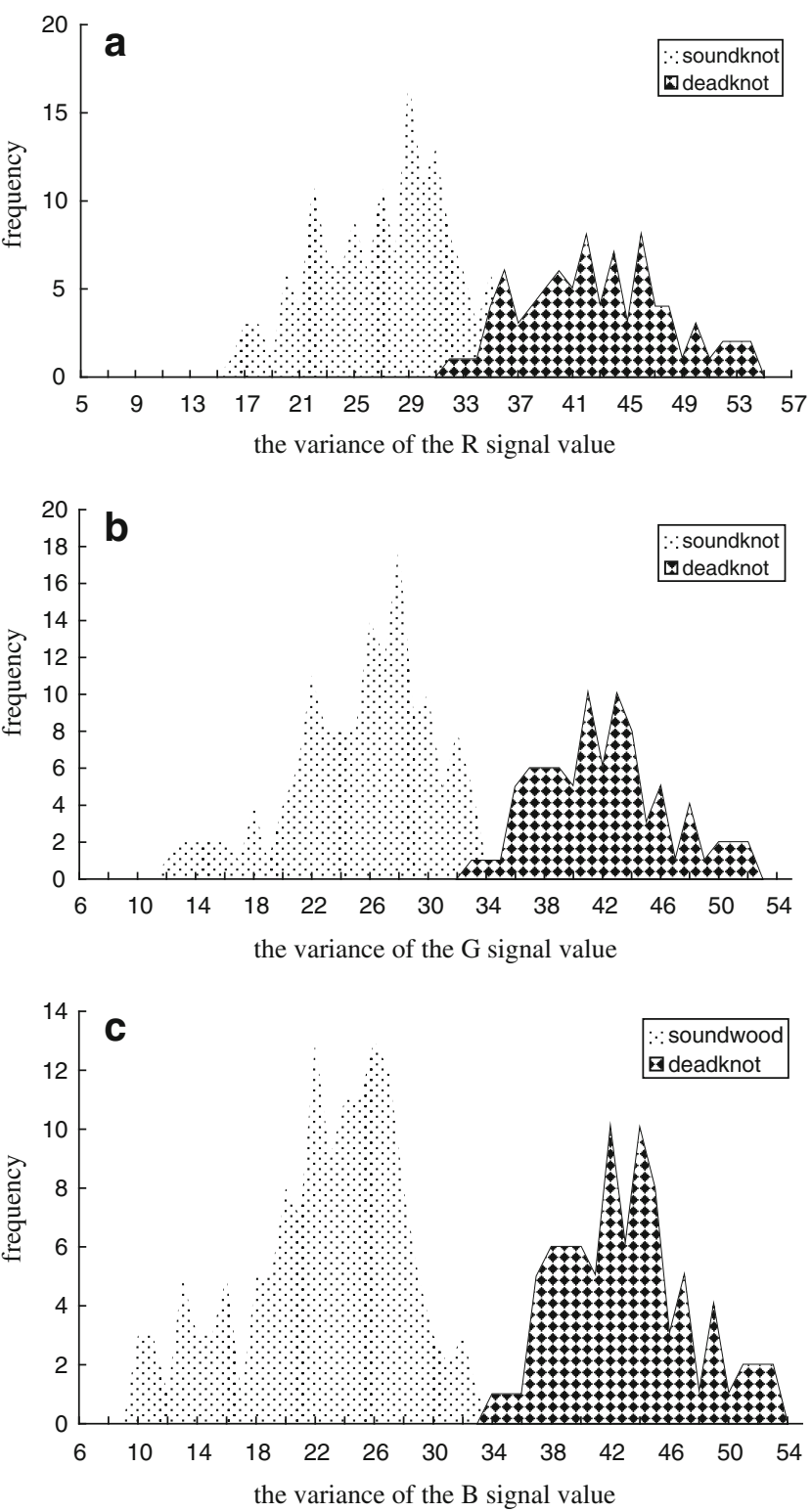

Fig. 7 The feature histograms of variances for R, G, and B signal values. a $R$ signal, b $G$ signal, c B signal

The whole intensity histogram of the contrast parameter is divided into two classes $\left(S_{1}\right.$ and $\left.S_{2}\right)$ at the threshold $k$. We set them as $S_{1}=[\min , \min +1, \ldots, k]$ and $S_{2}=[k+1, \ldots, \max ]$. The probability $\left(W_{1}\right.$ and $\left.W_{2}\right)$ and means $\left(m_{1}\right.$ and $\left.m_{2}\right)$ of the two classes are denoted by Eqs. 5 and 6 .

$$
\begin{aligned}
& w_{1}=\sum_{i=0}^{k} p(i), w_{2}=\sum_{i=k+1}^{255} p(i) \\
& m_{1}=\sum_{i=0}^{k} i p(i), m_{2}=\sum_{i=k+1}^{255} i p(i)
\end{aligned}
$$


Table 2 Values of recognition features and identifying results

$s k$ sound knot, $l k$ loose knot, NOPDR number of the potential defect regions

\begin{tabular}{|c|c|c|c|c|c|c|c|}
\hline \multirow[t]{2}{*}{ NOPDR } & \multicolumn{4}{|c|}{ Values of recognition features } & \multicolumn{2}{|c|}{ Identifying votes } & \multirow[t]{2}{*}{ Classification } \\
\hline & $\mathrm{M}_{\mathrm{G}}$ & $\mathrm{V}_{\mathrm{B}}$ & $\mathrm{V}_{\mathrm{G}}$ & $\mathrm{V}_{\mathrm{R}}$ & sk & $1 \mathrm{k}$ & \\
\hline$\# 1$ & 56 & 25.1 & 40.6 & 39.9 & 1.0 & 3.0 & $\mathrm{lk}$ \\
\hline$\# 2$ & 82.4 & 10.2 & 15.4 & 19.1 & 4.0 & 0 & sk \\
\hline
\end{tabular}

And the variances $\left(\sigma_{1}\right.$ and $\left.\sigma_{2}\right)$ of the two classes are denoted by Eq. 7 .

$\sigma_{1}(k)=\sum_{i=0}^{k}\left(m_{1}-i\right)^{2} p(i), \sigma_{2}(k)=\sum_{i=k+1}^{255}\left(m_{1}-i\right)^{2} p(i)$

The diversity between the $S_{1}$ and $S_{2}\left(\sigma_{B}\right)$ and the diversity among the $S_{1}$ or $S_{2}\left(\sigma_{W}\right)$ are denoted by Eqs. 8 and 9.

$$
\begin{aligned}
\sigma_{B}^{2} & =w_{1}\left(m_{1}-m_{t}\right)^{2}+w_{2}\left(m_{2}-m_{t}\right)^{2} \\
& =w_{1} w_{2}\left(m_{1}-m_{2}\right)^{2} \\
\sigma_{w}^{2} & =w_{1} \sigma_{1}^{2}+w_{2} \sigma_{2}^{2}
\end{aligned}
$$

where $m_{t}$ is the mean value of the whole image.

The variance of the whole intensity histogram is denoted by Eq. 10 .

$\sigma_{t}^{2}=\sum_{i=0}^{255}\left(i-m_{t}\right)^{2} p(i)=\sigma_{B}^{2}+\sigma_{w}^{2}$

To select the optimum threshold $k^{*}$ automatically, the evaluation index is denoted by Eq. 11 . When the value of $\eta(k)$ is maximum, the optimized threshold results are accomplished

$\eta(k)=\frac{\sigma_{B}^{2}}{\sigma_{t}^{2}} \eta\left(k^{*}\right)=\underset{\min <k<\max }{\operatorname{Max}}(\eta(k))$
The result of segment at $k^{*}$ is denoted by Eq. 12 .

$f_{N_{\mathrm{r}} \times M_{\mathrm{c}}}=\left\{\begin{array}{c}255 \text { if contrast } \geq k^{*} \\ 0 \text { if contrast }<k^{*}\end{array}\right.$

A morphological operation, which included a dilating and eroding operation, was conducted to eliminate the noise after segmenting. The potential defects are still discrete points and the image can be denoted as a set of \{clear wood, potential defects $\}$. To form the complete potential defects area, the four-adjacent connectedness component labeling operation was applied (Rosenfeld and Kak 1976). All potential defect regions were found, and each such region was given a different label. Then the image could be denoted as the set of $\left\{R_{1}, R_{2}, \ldots, R_{n}\right\}$ after the above operation.

Here a rule-based approach, which was proposed by the authors previously (Hu et al. 2004), was adopted to identify the potential defect region. For each of the potential defect region detected by the above mentioned procedure, the statistical color features were computed from the image data. Currently, four basic features, which were variances of the signal $R, G, B\left(V_{R}, V_{G}, V_{B}\right)$, and the mean of the signal $\mathrm{G}\left(\mathrm{M}_{\mathrm{G}}\right)$, had been derived to identify sound knots and loose knots. Based on these four-basic features, each potential defect area has a confidence vector to describe the belief that the area belongs to a sound knot or a loose knot. To properly determine the recognition rules, 222 samples, which consisted of 142 sound knot and 80 loose knot regions, were used as a set of training data to generate thresholds of rules. For every training sample, the fourbasic feature values were computed and then the individual

Table 3 Measured accuracies of the detection system

\begin{tabular}{lllllccc}
\hline Classification & $\begin{array}{l}\text { Total } \\
\text { samples }\end{array}$ & $\begin{array}{l}\text { Samples } \\
\text { located } \\
\text { correctly }\end{array}$ & $\begin{array}{l}\text { Locating } \\
\text { accuracy (\%) }\end{array}$ & $\begin{array}{l}\text { Samples } \\
\text { identified } \\
\text { accurately }\end{array}$ & $\begin{array}{l}\text { Identifying } \\
\text { accuracy (\%) }\end{array}$ & $\begin{array}{l}\text { Final detecting } \\
\text { accuracy (\%) }\end{array}$ & $\begin{array}{l}\text { Total detecting } \\
\text { accuracy (\%) }\end{array}$ \\
\hline Sound knot & 94 & 89 & 94.7 & 86 & 96.6 & 94.7 \\
Loose knot & 86 & 84 & 97.6 & 83 & 98.8 & 96.5 \\
\hline
\end{tabular}

Locating accuracy $=\frac{\text { Samples located correctly }}{\text { Total samples }}$;

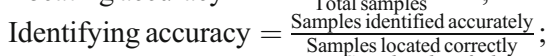

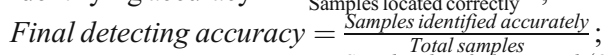

Total detecting accuracy $=\frac{\begin{array}{c}\text { Total samples } \\ \text { Samples identified accurately }(\text { Sound knot }+ \text { Loose knot })\end{array}}{\text { Total samples }(\text { Sound knot }+ \text { Loose knot })}$ 
population distributions (feature histograms) of these given features were formed. Thresholds were visually determined by the histogram of individual features. All the evidence functions and recognition rules are shown in Table 1. For each potential defect area, such functions and rules assign individual values of one or zero to its confidence value. The procedure applying rules is in fact a voting process to decide whether the potential defect area should be classified into a sound or loose knot.

The total vote of the potential defect area can be expressed as follows:

$$
\begin{aligned}
& \mathrm{TV}_{1}(\text { soundknot })=\sum_{\text {countl }=1}^{\operatorname{Tr}^{\prime}} \operatorname{Cv}(F(\text { count } \mathrm{l})) \\
& \mathrm{TV}_{1}(\text { looseknot })=\sum_{\text {countl }=1}^{\operatorname{Tr}{ }^{\prime}} \operatorname{Cv}(F(\text { count }))
\end{aligned}
$$

Where $F$ (countl) is the countlth feature; $\operatorname{Tr}^{\prime}$ is the total number of the feature; $\mathrm{TV}_{1}$ ( soundknot), $\mathrm{TV}_{1}$ (looseknot) is the total votes for the classification of sound knot and loose knot. Here $\operatorname{Tr}^{\prime}$ is equal to $4\left(\mathrm{M}_{\mathrm{G}}, \mathrm{V}_{\mathrm{R}}, \mathrm{V}_{\mathrm{G}}, \mathrm{V}_{\mathrm{B}}\right)$.

\section{Results}

Sound and loose knot defects are associated with surface color and its texture feature. These characteristics can be used to detect knots using a CCD camera. As shown in Fig. 3, two knots (one sound knot and one loose knot) are manifested well in the sample image. Under the study, the gray image was used to detect the potential defect regions and the R, G, and B signals were used to identify whether the defect was a sound or a loose knot.

To accurately locate potentially defective regions, Otsu's algorithm was used to automatically select the threshold $\left(k^{*}\right)$ from the contrast parameter histogram based on the gray image. As shown in Fig. 4, the objective image was correctly separated into a binary picture that expressed the potential defects and clear wood areas. Some small false potential defect regions are scattered in the binary image because of the discontinuity of defect contours. As shown in Fig. 5, one sound knot and one loose knot in the sample were located correctly by the proposed image processing methodology.

To identify the sound and loose knots, the identifying rules were built based on four basic color statistical features. A series of samples containing sound knots and/ or loose knots, which were selected at random from a Japanese Glulam manufacturing factory named Chugoku Mokuzai Co. Ltd, were used as training data to form the feature histograms. Thresholds that separated the population distributions of features into discrete sets and created the identifying rules were visually determined from the feature histograms. As shown in Figs.6 and 7, the features $\mathrm{M}_{\mathrm{G}}, \mathrm{V}_{\mathrm{R}}, \mathrm{V}_{\mathrm{G}}$, and $\mathrm{V}_{\mathrm{B}}$ are valuable for identifying sound knots from loose knots. Considering the manifestation of all four basic features, the identifying rules were created as shown in Table 1. One sound knot and one loose knot of the example were used as an example to explain the processing procedure of the system and to demonstrate the efficiency of the identifying rules. The feature values and the identifying results are shown in Table 2 . The results indicate that all of the two types of defects had been identified accurately.

The other series of 160 samples containing single or multiple sound and/or loose knots, which was totally different from the training set, were selected at random to be detected by the system proposed in this study in order to test the efficiency and accuracy of the system. There were 94 sound knots and 86 loose knots on the surfaces of these samples. As shown in Table 3, the locating accuracies of sound knots and loose knots were $94.7 \%$ and $97.6 \%$, respectively, and therefore, the identifying accuracies of sound knots and loose knots were $96.6 \%$ and $98.8 \%$, respectively. The final detecting accuracies of sound knots and loose knots were 91.5\% and $96.5 \%$, respectively. The overall detecting accuracy for the two types of defects was $93.9 \%$. It was found that false negatives, which meant the missed detection of a defect, represented the major part of the false detection when knots with low color variation with respect to surrounding clear wood. False positives happened when sound knots contained cracks and were misclassified as dead knots. The rule-based technology is an efficient way to identify the defects classification. However, additional features should be discussed as other defects such as cracks need to be recognized or current defects need to be identified better.

\section{Conclusion}

The image processing method based on the GLCM parameters was developed and tested to locate the potential defect regions of sound knots and loose knots in sugi. The results of this study showed that the surface texture and color features can be used together to detect sound knot and loose knot defects that are well manifested in RGB images. The proposed vision system is an efficient means of detecting sound knots and loose knots.

Acknowledgments The Project was sponsored by the Department of Finance of Guangdong Province (Project No.2008A020100013) and State Key Laboratory of Subtropical Building Science, South China University of Technology. 


\section{References}

Conners RW, Kline DE, Philip AM, Thomas HD (1997) Machine vision technology for the forest products industry. Computer 30:43-48

Haralick RM, Shanmugam KD, Instein I (1973) Texture features for image classification. IEEE Transactions on System Man and Cybernetics 3:610-621

Hu CS, Tanaka C, Ohtani T (2002) Locating and identifying holes and splits on sugi by the displacement laser sensor. J Wood Sci 49:492-498

$\mathrm{Hu}$ CS, Tanaka C, Tadashi O (2004) Locating and identifying sound knots and dead knots on sugi by the rule-based color vision system. J Wood Sci 51:115-122
Johansson M, Nystrom J, Ohman M (2003) Prediction of logintudinal shrinkage and bow in Norway spruce studs using scanning techniques. J Wood Sci 49:291-297

Koivo AJ, Kim CW (1989) Automatic classification of surface defects on Red Oak boards. For Prod J 39:22-30

Otsu N (1979) An automatic threshold selection method based on discriminate and least squares criteria (in Japanese). Denshi Tsushin Gakkai Ronbunshi 63:349-356

Portala JF, Ciccoteli J (1992) Nondestructive testing techniques applied to wood scanning. Ind Metrol 2:299-307

Rosenfeld A, Kak AC (1976) Digital picture processing. Academic, New York

Szymani R, McDonald KA (1981) Defect detection in lumber: state of the art. For Prod J 31:34-43 